\title{
Analysis of the influence of grassland degradation in Du Meng County of Heilongjiang Province
}

\author{
Limei Zhang ${ }^{1,3}$, Lingjun Meng ${ }^{1,4}$, Xueping Zhang ${ }^{1,2}$ and Shufeng Zheng ${ }^{5 *}$
}

1. College of Geographical Sciences, Harbin Normal University, Harbin 150025, China.

2. Key Laboratory of Remote Sensing Monitoring of Geographic Environment,College of Heilongjiang Province, Harbin Normal University, Harbin 150025,China.

3. School of History, Cultural Tourism, Heilongjiang University,Harbin 150080,China.

4. School of Continuing Education, Heilongjiang University, Harbin 150080, China.

5. School of Government, Heilongjiang University, Harbin 150080,China.

* Corresponding author:Shufeng ZHENG Email: zsf7415@163.com

Key words:The grassland productivity; Human influence factors; Climate factors; Dumeng County

Abstract: In recent 50 years, because of the interference of natural factors and human activities, the quality, productivity and the carrying capacity were decreased of Dumeng Country grassland in Heilongjiang Province. According to the division of county, Dumeng County township is determined disturbed grassland and none disturbed grassland in this study. Using sensing data of satellite remote, which is getting unit NDVI integral of every land. Analyzing the influence of human factors on grassland productivity by calculating the grassland relative degradation index. Finally, the relative degradation index and climate of the grassland productivity and human influence factors were analyzed. According to the result of grassland degradation index, combined with the villages and towns cultural statistics, found out the main human factors and affected the grassland productivity. Results show that the main human factors affect the Dumeng county grass productivity is the total population and the number of large livestock. And the principal component analysis results show that the load of the first and second principal components reached $71.635 \%$; The correlation coefficient of Dumeng county total population and relative grass degradation index reached 0.733 . The correlation coefficient of the number of large livestock and relative grass degradation index reached 0.603 . The correlation level both reached 0.01 level. According to two regression methods based on the relative degradation index comparison, found that the curve regression method for Dumeng county each villages and towns of grassland degradation index of fitting effect is good, the main human factors affecting the majority of villages and towns grassland productivity is the total population.

\section{Introduction}

Grassland is one of the most important and widely distributed ecosystems in terrestrial ecosystems. The influence of grassland ecosystems in the global change is receiving more and more attention (Scurlock, 2002). The grassland ecosystem plays an important role in the global carbon cycle and climate regulation (Scurlock, 2002;Shilong Piao, 2004). Traditional pastoral areas, especially the Dumeng county and some other important livestock bases, because of the growing population pressure and the increase of the market demand for animal products, grazing capacity is more than carrying capacity.Overgrazing lead to the destruction of the pastures,so that the area of natural grassland decreased.

In monitoring the effect of large scale grazing on grassland degradation, Pickup, etc. (1994) 
discussed the way of remote sensing can be counted on to get a series of indicators, such as rain season average distribution trend of vegetation coverage and the distance from the water, the change of and the loss rate of grassland coverage after rain, to calculate the relative difference of foliage, the mixture of these methods provide a potential for monitoring grassland degradation;Pickup (1995) proposed a simple model to assess based on the rate of grassland degradation and the productivity of grassland, in order to overcome the difficulty to assess land degradation in the use of biological and economic yields. While the rate of grassland degradation and the productivity of grassland is easily obtained from the remote sensing data, the remote sensing data can be used to evaluate the grassland degradation indirectly;According to NDVI and MSDI contrast analysis of five different ecosystems, Quangong Chen etc.(1998)think MSDI is a beneficial complement for NDVI in grassland degradation research.Application of remote sensing and geographic information system (GIS), ground survey and other kinds of technology, through the contrast analysis of dari County of Qinghai 1985-1997 ground observation data and remote sensing image, establishment of grassland resources remote sensing dynamic monitoring model, and analysis of the quantity of grassland resources degradation in the county and the spatial distribution, the grassland production, stocking capacity and grassland classification figure can be drawn;Eve et al. (1999) on the AVHRR thermal research for many years, found that the image best reflects the status of grassland degradation. And the degradation distribution figure was made by this. Tanser et al. (1999) using the way of remote sensing monitoring the degradation types of South Africa half arid landscape, puts forward a mobile standard deviation index (MSDI), with the TM band 3 to describe the stability of the landscape. The study found that the MSDI value has a significant difference between the four different condition grass.Jun Tu etc. (1999) According to remote sensing technology on the northern slope of Bayanhar, Dari County of Qinghai Province to analyse the causes of withdrawal of alpine meadow, the distribution, area and the remote sensing interpretation signs, the study area is divided into 5 types of alpine grassland, 2 sub categories and 3 degraded grasslands; Liu Zhiming et al (2001) used in the west of Jilin Province in 1996 and autumn 1986 Landsat TM data, combining recognition methods of computer supervised classification and unsupervised classification to interpretate the grassland.

\section{Research area and research methods}

\section{Introduction of study area}

Durbat monggol nationality autonomous county is located between Qiqihar and Daqing $\operatorname{city}\left(45^{\circ} 30^{\prime} \mathrm{N} \sim 47^{\circ} 28^{\prime} \mathrm{N}, 123^{\circ} 44^{\prime} \mathrm{E} \sim 126^{\circ} 38^{\prime} \mathrm{E}\right)$, under the jurisdiction of Daqing city in the administration. Southwest border with jilin province. It governs four towns (Taikang,Yantong,Hujitumo, Talaha), 7townships (Jiangwan, Yixin, Kerrtai, baiyinuole, Yaoxin, Bayanchagan, Aolinxibo), four committees; An area of $6427 \mathrm{~km} 2$;A total population of 2.44 million, of which the agricultural population of 15.6 million.Geomorphic type belongs to the the first level alluvial terraces of Songhua river, Nenjiang. No mountains, within the territory of terrain from north to south gradually low, elevation is between $126-160 \mathrm{~m}$. It is located in the north temperate Eurasian Continental in the eastern margin of the continental monsoon climate zone, influenced by Mongolian inland cold air and Ocean warm current and monsoon, cold and dry winter long (November-February ), summer is short (June-August) warm and rainy, spring (March to May) and autumn (September- October) monsoon alternately, temperature changes sharply, more wind. 


\section{Situation of grassland degradation and influence of cultural factors in Dumeng Country}

Population is one of the most important factors in human factors, and the most dynamic factor of grassland degradation, which cause the changes of intensity and space of grassland utilization in some respects such as quantity structure, methods and product demand; Economic development is an important factor in grassland use intensity change, influencing the quantity and intensity of grassland utilization change, mainly by herdsmen management behavior, animal husbandry, the transfer of animal husbandry labor and the internal structure adjustment,etc; Urbanization is the important factor affecting grassland utilization pattern; Institutional factor is the foundation and the guarantee, which makes cultural factors play a role of grassland degradation. It is the fundamental factor of grassland degradation, with a mandatory reality effect on grassland use change. With the increase of population and ecological environment deterioration, the survival pressure, the rapidly development of sheep industry, the heavy use of grassland, light management, protection forest grassland has become a main pasture on livestock and grassland degrade gradually. Due to a lack of scientific management, excessive reclamation and construction, the grass protection appears repeatedly, in order to pursue economic benefits, people destroyed lots of grassland for farming, result in grassland area is decreasing. From 2001 to 2005, because of the implementation of conversion forest grass policy, grassland area increased, and part of the grassland is ungrazed.Even if most of the grassland will be affected by the interference of human activities, the degree has been greatly weakened.

The $\sum$ NDVI of growth season grassland of each villages and towns in May to September from 2001 to 2005 is obtained by statistical analysis of growth season MODIS Image in May to September from 2001 to 2005 by Using the function of ArcGIS spatial analysis. Finally, Using formula 5-1 calculate relative degradation index of each township.As Shown in Fig.1:

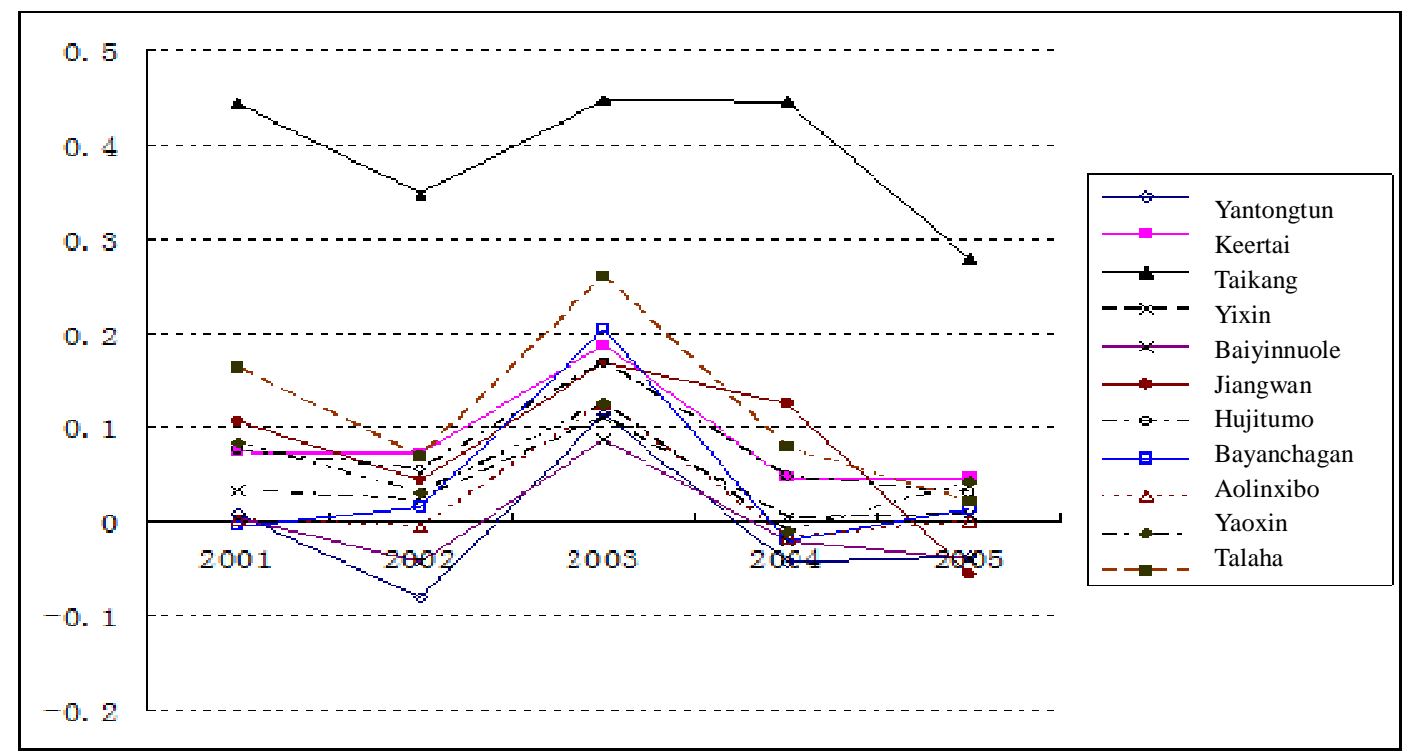

Fig.1 2001-2005, Relative degradation index of growth season(May to September)of Dumeng county

\section{Principal component analysis of cultural factors of grassland productivity}

There is a certain correlation between several cultural factors affecting grassland productivity of Dumeng County. This paper will select several major human impact factors by a principal component analysis method for the research analysis behind. Principal component analysis use 
SPSS software. Principal component analysis results are as follows: the variance of the common factor except the number of sheep, variance of the other factors are very high, it shows that the extraction of the components can be a good description of these variables.Among the variance of the common factor,the characteristic value of the first principal component was 2.134 , the characteristic value of the second principal component was 1.447 , and only the characteristic value of the first two factors is greater than 1,\% of Variance is the percentage of variance explained by each component accounted for the total variance, which is the percentage of characteristic value of each factor accounted for the sum of characteristic value. Cumulative is cumulating percentage of each factor variance accounted for the total variance from top to bottom the sum of the characteristic value of the first two factors account for $71.64 \%$ of the total variance, which means the first two factors explain $71.64 \%$ of the original five variables. Sums of Squared Loadings Extraction is the result of the factor extraction, which is the square sum of the load of the non rotating factor. The characteristic values of each factor (or component) are given to account for the percentage of the total variance and the cumulative percentage of the total variance. According to the factor loading matrix, it can be seen that correlation between the first principal component and the total population and the total number of households are high, and correlation between the two main composition and sheep units and livestock are higher. Because of the existence of a greater correlation between total population and the total number of households, large livestocks and sheep unit itself, only select the total population of the township and large livestock number (converted into sheep units) to study about human impact factors of the relative degradation index behind.

\section{Regression analysis of grassland degradation in Dumeng County}

According to the data of population and large livestock in Durbat monggol nationality autonomous county to have a regression analysis of grassland degradation index. And finally determine the best fitting equation based on the probability value(Sig) corresponded to the regression curve test statistics and the coefficient of determination(R2).

Using SPSS statistical analysis software to have a multivariate linear regression analysis of the durbat monggol nationality autonomous county township grassland degradation index, obtains the binary linear equation of each township grassland relative degradation index (RDI) is as follows ( $\mathrm{P}$ refers to the total rural population, L refers to the unit number converted into sheep ) :

Yantong: $\quad$ RDI $=0.115-3.03 \times 10-7 \mathrm{P}-4.89 \times 10-7 \mathrm{~L}$

Keertai: $\quad$ RDI $=0.187-4.69 \times 10-6 \mathrm{P}-1.54 \times 10-7 \mathrm{~L}$

Taikang: $\quad$ RDI $=-2.372+1.953 \times 10-5 \mathrm{P}+2.394 \times 10-5 \mathrm{~L}$

Yixin: $\quad$ RDI $=0.092+7.338 \times 10-7 \mathrm{P}-1.88 \times 10-7 \mathrm{~L}$

Baiyinnuole: $\quad \mathrm{RDI}=0.058-6.35 \times 10-7 \mathrm{P}+4.087 \times 10-7 \mathrm{~L}$

Jiangwan: $\quad$ RDI $=0.173-4.1 \times 10-6 \mathrm{P}-6.63 \times 10-7 \mathrm{~L}$

Hujitumo: $\quad$ RDI $=-0.079+8.048 \times 10-6 \mathrm{P}-2.51 \times 10-7 \mathrm{~L}$

Bayanchagan: $\quad \mathrm{RDI}=0.011+6.254 \times 10-7 \mathrm{P}-1.03 \times 10-7 \mathrm{~L}$

Aolinxibo: $\quad$ RDI $=0.244-1.17 \times 10-5 \mathrm{P}+1.473 \times 10-7 \mathrm{~L}$

Yaoxin: $\quad$ RDI $=0.023-4.88 \times 10-8 \mathrm{P}-3.31 \times 10-7 \mathrm{~L}$

Talaha: $\quad$ RDI $=-0.024+8.79 \times 10-6 \mathrm{P}+7.446 \times 10-7 \mathrm{~L}$

The Coefficient of multipiecorrelation $\backslash \mathrm{R}$, Coefficient of determination R2,Corrected value of $\mathrm{R} 2$ and the probability value(Sig) in the fitting equation of each township grassland degradation index are shown in table 1 . Probability values $(\mathrm{Sig})$ are greater than 0.05 , and the effect of 
fitting is not ideal.

Table 1. The grassland degradation relative index of multivariate linear regression statistical model in Dumeng County

townships

\begin{tabular}{|c|c|c|c|c|}
\hline Township & $\begin{array}{c}\text { Coefficient of } \\
\text { multipiecorrelation } \\
R\end{array}$ & $\begin{array}{c}\text { Coefficient of } \\
\text { determination } R^{2}\end{array}$ & $\begin{array}{c}\text { Corrected } \\
\text { value of } R^{2}\end{array}$ & $\begin{array}{l}\text { Probability } \\
\text { value ( } \mathrm{Sig})\end{array}$ \\
\hline Yantong & 0.202 & 0.041 & 0.004 & .339 \\
\hline Keertai & 0.883 & 0.779 & 0.55 & 0.221 \\
\hline Taikang & 0.911 & 0.831 & 0.66 & 0.169 \\
\hline Yixin & 0.957 & 0.916 & 0.83 & 0.084 \\
\hline Baiyinnuole & 0.750 & 0.750 & 0.12 & 0.438 \\
\hline Jiangwan & 0.949 & 0.900 & 0.80 & 0.100 \\
\hline Hujitumo & 0.944 & 0.890 & 0.78 & 0.110 \\
\hline Bayanchagan & 0.428 & 0.183 & 0.63 & 0.817 \\
\hline Aolinxibo & 0.973 & 0.947 & 0.89 & 0.053 \\
\hline Yaoxin & 0.404 & 0.163 & 0.67 & 0.837 \\
\hline Talaha & 0.502 & 0.252 & -0.49 & 0.748 \\
\hline
\end{tabular}

According to the probability value(Sig) corresponded to the regression curve test statistics and the coefficient of determination(R2) combined with the regression curve finally determine the best fitting and curve equation of the grassland degradation index (RDI) of every townships and the whole Durbat monggol nationality autonomous county.

\section{Conclusion}

Through regression analysis, we can found that the large livestock is the main human factors affecting the grass productivity of the whole Durbat monggol nationality autonomous county, but the main influencing factor of the villages and towns is different. Population is the main human factor affecting the grassland productivity of Keertai, Baiyinnuole, Jiangwan, Hujitumo and Aolinxibo. The number of large livestock is the main human factors affecting the grass productivity of other towns including Taikang town the seat of county government.

\section{Acknowledgements}

The project was financially supported by the auspices of National Natural Science Foundation of China (No. 41101049, 41471037, 41371072, 41430857), Distinguished Young Scholar of Harbin Normal University (No. KGB201204), University Nursing Program for Young Scholars with Creative Talents in Heilongjiang Province (No, UNPYSCT-2015054) and Excellent Youth Scholars of Northeast Institute of Geography and Agroecology, Chinese Academy of Sciences (No. DLSYQ2012004). Thanks for the help from my colleges. Thanks to the support of facilities and sample land of Dumeng. 


\section{Reference}

[1] Chen, Q., Acta prataculturae Sinica, 1998, 7 (2): 58-63. in Chinese

[2] Chen Y.Y., The future development of IGBP. Progress in the earth science, 2001, 16 (1): 15-17. in Chinese

[3] Liu, H.F.,The effects of global climate change on ecological factors in Songnen grassland water heat. Journal of ecology, 2000, 20 (6): 958-963. in Chinese

[4] Ding, Z., Tong Q.X., Zheng L.F., et al. Application of meteorological satellite image data to the preliminary analysis

of the measuring methods of grassland biomass. Arid zone research, 1986, (2) : 8-13. in Chinese

[5] Ge, C.H., Liu, C., Characteristics and applications of resolution imaging spectrometer (MODIS) in the United States of America (EOS), remote sensing data, 45, (3): 48-2000. in Chinese

[6] Guo, J.X.,Jiang, J.C., A comparative study of the treatment method of saline alkali grassland in Songnen Plain.

Chinese Journal of Applied Ecology, 1998, 9 (4): 425-428. in Chinese

[7] HE, N.P., Wu, L., Zhou, D.W., Grazing on agriculture and animal husbandry of Songnen Plain staggered effect of

grassland area of shelterbelt. Chinese Journal of Applied Ecology, 2004, 15 (5): 795-798. in Chinese

[8] Huang, F., Bao, Y.Y., Western Songnen plain ecological fragile district spatial and temporal changes of land use.

Journal of Northeast Normal University (Natural Science Edition), 2002, 34 (1): 105-110. in Chinese

[9] He, 1.,An S.Z.,Jin, G.L.,Fan, Y.M.,Zhan Y., Degraded Seriphidium transiliense desert grassland hyperspectral

characteristics. Journal of grassland, 2014,2, 271-275. in Chinese

[10] Tianjie Lei, Jianjun Wu, Xiaohan Li, Guangpo Geng, Changliang Shao, Hongkui Zhou, Qianfeng Wang, LeizhenLiu.

A new framework for evaluating the impacts of drought on net primary productivity of grassland Science of The Total

Environment, 2015,536(1): 161-172.

[11] Karin Glaser, Anke Kuppardt, Jens Boenigk, Hauke Harms, Ingo Fetzer, Antonis Chatzinota. The influence of environmental factors on protistan microorganisms in grassland soils along a land-use gradient Science of The Total

Environment, 2015,537(15): 33-42.

[12] Hongyan Cai, Xiaohuan Yang, Xinliang Xu. Human-induced grassland degradation/restoration in the central Tibetan Plateau: The effects of ecological protection and restoration projects. Ecological Engineering, 2015, 83:112-119. 